\title{
Multiple mating in a natural population of the isopod Sphaeroma rugicauda; evidence from distorted ratios in offspring
}

\author{
D. J. Heath, \\ J. R. Ratford, \\ B. J. Riddoch and \\ D. Childs
}

Department of Biology, University of Essex, Colchester, U.K.

Fertilised females of the isopod Sphaeroma rugicauda were collected from a natural population. Offspring ratios at a diallelic phosphoglucose isomerase locus were determined for individual broods. Out of 211 broods 37 showed significant departures from Mendelian expectations. The pattern of distortion in broods segregating for two genotypes was consistent with a hypothesis of multiple mating under which two males contribute equally to the brood. The pattern of distortion in broods segregating for three genotypes was also compatible with multiple mating. However in this case the ratios deviate from those expected on the basis of the two male genotypes contributing equally to each brood.

\section{INTRODUCTION}

Multiple mating appears to be common in some organisms, e.g., insects, (Prout and Bundgaard, 1977) and provides a situation with major evolutionary implications. It provides the opportunity for sperm competition (Smith, 1984) and selection for mechanisms of sperm precedence, where different males father different number of offspring (Waage, 1986). It may also have genetic consequences. It decreases the relatedness of offspring from a single female and reduces subsequent inbreeding (Johnson, 1982; Sassman, 1978) and can also lead to additional opportunities for sexual selection in polymorphic systems, a topic that is attracting increased attention (Endler, 1986).

Multiple mating has been demonstrated in terrestrial isopods of the genera Porcellio and Armadillidium (Sassman, 1978; Johnson, 1982). These isopods are long-lived and the females can be inseminated at any time before a parturial moult (Ridley, 1983). Subsequent broods of offspring may be produced after further moults, with or without further mating, because sperm can be stored. While this type of life history is clearly conducive to multiple mating it has always seemed to be less likely in aquatic isopods such as Asellus and Sphaeroma. These species are annual and usually produce only one brood in their lifetime. Most importantly, mating can only take place in a short period (24 hours in Asellus) after the female has moulted and before the brood pouch has formed (Ridley, 1983). This reduces the time available for mating, a constraint that will be exacerbated in an intertidal isopod such as Sphaeroma, which is only active during periods of tidal immersion (Heath and Khazaeli, 1985).

A population of $S$. rugicauda has been the subject of an intensive investigation of a diallelic phosphoglucose isomerase (PGI) polymorphism (Heath et al., 1988). This involved (amongst other things) the collection of fertilised females from the population and the examination of the genotypic ratios in their broods. Data of this form can be used to demonstrate whether there is multiple mating (Sassman, 1978).

\section{METHODS}

Fertilised females were taken from a population of Alresford Creek, Essex (TM 082194). Females were kept isolated in petri dishes of seawater until 


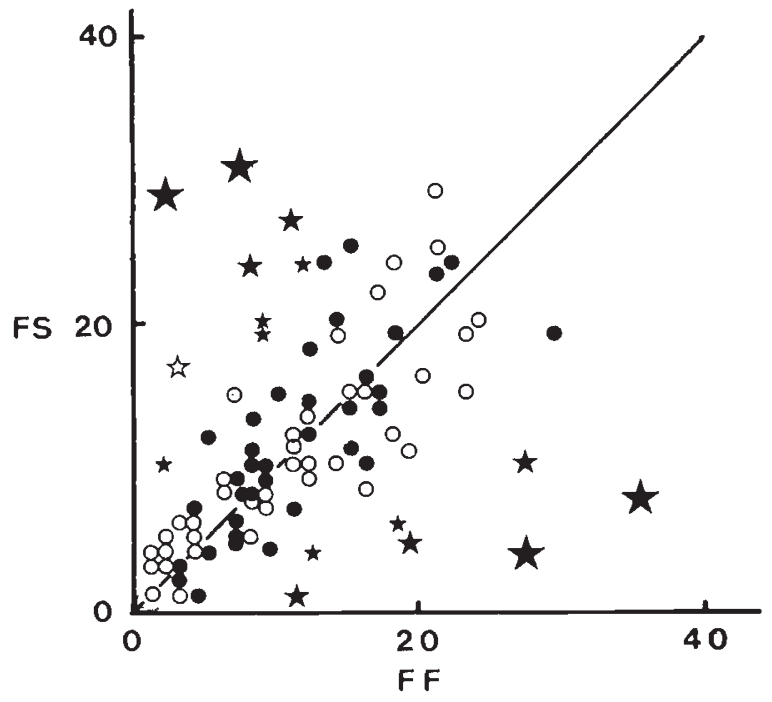

Figure 1 Numbers of FF and FS offspring in broods of FF females (solid symbols) and FS females (open symbols). Circles: broods not deviating significantly from $1: 1$. Stars: broods with significant deviations $\star P<0.05, \star P<0.01$, $\star P<0.001$, Diagonal line, ratio of $1: 1$.

they had released their young after which both mother and offspring were electrophoresed to determine their PGI genotype, following the method of Edwards (1981). The two alleles present are labelled $\mathrm{F}$ (fast) and $\mathrm{S}$ (slow).

\section{RESULTS}

Fig. 1 shows broods from 51 FF and 43 FS mothers segregating for FF and FS offspring. In a total of 94 broods 16 showed significant deviations from $1: 1$ ratios when tested by $\chi^{2}$. Seven had a sig-

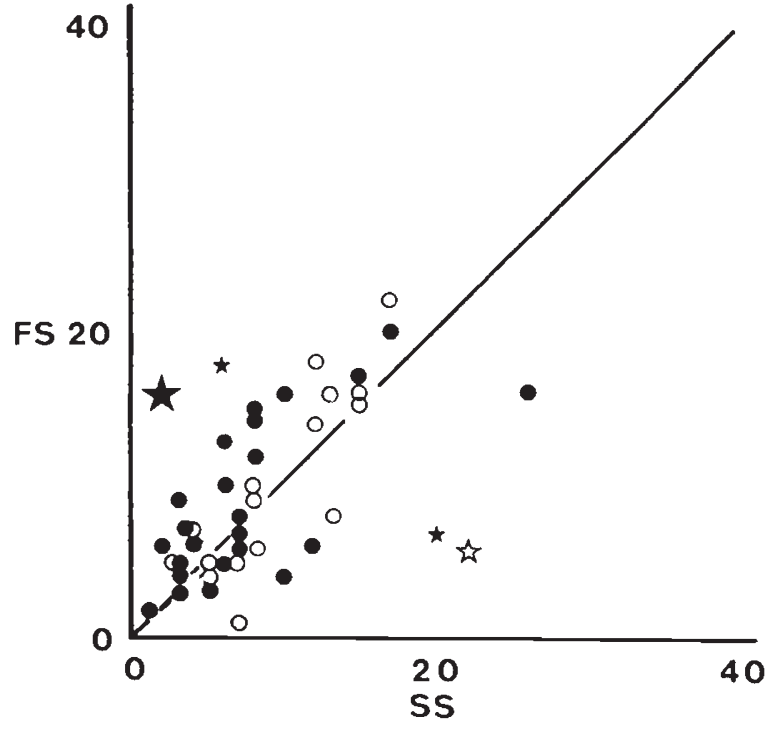

Figure 2 Numbers of FS and SS offspring in broods of FS females (open symbols) and Ss females (solid symbols). For other symbols see fig. 1 .

nificant excess of FF and nine an excess of FS. All but one came from FF mothers a highly significant difference in the proportion of distorted broods between the two types of mother $\left(\chi^{2}=12 \cdot 1\right.$, $1 \mathrm{df} P<0.01)$. The seven broods with an excess of FF are homogeneous with respect to genotype ratios (table 1) with an overall frequency of FF of 0.797. The eight broods from FF mothers with an excess of FS are also homogeneous, with a frequency of FS of $0 \cdot 755$. The one segregating brood from an FS female gives a frequency of FS of 0.85 (table 1 ).

Fig. 2 shows broods from 18 FS and 28 SS mothers segregating for FS and SS offspring. There

Table 1 Offspring genotype ratios in distorted broods segregating for two genotypes

\begin{tabular}{|c|c|c|c|c|c|c|c|c|c|}
\hline \multirow{2}{*}{\multicolumn{2}{|c|}{ Female }} & \multirow[b]{2}{*}{$N$} & \multirow[b]{2}{*}{$n$} & \multicolumn{3}{|c|}{$\begin{array}{l}\text { Offspring genotypes } \\
\text { and ratios }\end{array}$} & \multirow[b]{2}{*}{$\chi^{2}$} & \multirow[b]{2}{*}{$P$} & \multirow[b]{2}{*}{ Frequency } \\
\hline & & & & $\mathrm{FF}$ & FS & SS & & & \\
\hline 1) & \multirow{2}{*}{$\mathrm{FF}$} & \multirow{2}{*}{36} & $\{7$ & 149 & 38 & - & $3 \cdot 769$ & \multirow{3}{*}{$\begin{array}{l}\text { ns } \\
\text { ns }\end{array}$} & 0.797 \\
\hline 2$\}$ & & & $\{8$ & 60 & 185 & - & $9 \cdot 887$ & & 0.755 \\
\hline 3 & FS & 42 & 1 & 3 & 17 & - & - & & 0.850 \\
\hline 4 & FS & 17 & 1 & - & 6 & 22 & - & \multirow{3}{*}{ ns } & 0.786 \\
\hline 5) & \multirow{2}{*}{ SS } & \multirow{2}{*}{25} & $\{2$ & - & 34 & 8 & $1 \cdot 287$ & & 0.809 \\
\hline 6$\}$ & & & $\left\{\begin{array}{l}1 \\
1\end{array}\right.$ & - & 7 & 20 & - & & 0.741 \\
\hline
\end{tabular}

$N=$ number of non-distorted broods.

$n=$ number of distorted broods.

$\chi^{2}=$ heterogeneity $\chi^{2}$ between broods (degrees of freedom $=n-1$ ), $P=$ probability, ns = not significant.

Frequency $=$ frequency of most common genotype. 
are four significant deviations from $1: 1$ out of a total of 46, two in each direction. Three originated from SS females and one from an FS female. The frequencies of the common genotype $(0 \cdot 74-0 \cdot 81)$ in all four broods are rather similar to those in the preceding set of data. Indeed if the actual genotypes involved in the broods are ignored and individuals are merely classified as to whether they belong to the common or the rare genotype then the six sets of data are homogeneous $\left(\chi^{2}=2 \cdot 193\right.$, $\mathrm{df}=5, P>0.05)$, with a frequency of the common genotype of 0.777 .

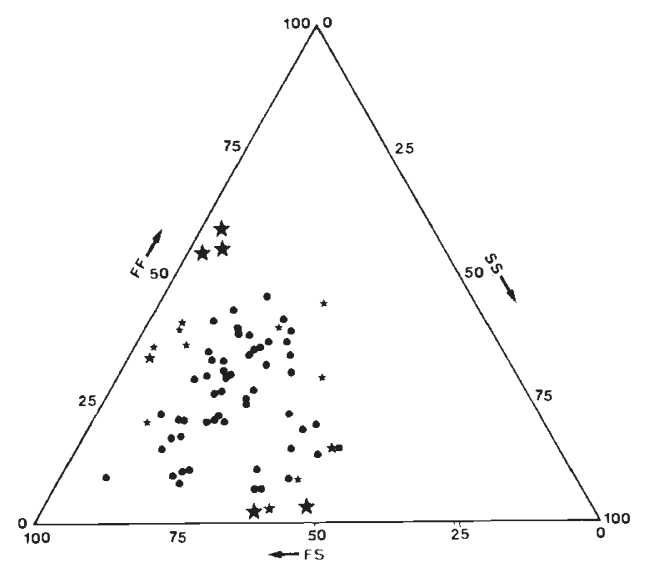

Figure 3 Relative frequencies of FF, FS and SS offspring of FS females. Cirlces: broods not deviating significantly from 1 : 1 . Stars: broods with significant deviations $\star P<0.05$, $\star P<0.01, \star P<0.001$.

Fig. 3 shows the broods produced by FS females segregating for all three genotypes. 17 of the 71 broods show significant deviations from the expected ratio of $1: 2: 1$, and these fall into three clusters. Five broods have a deficiency of FF, an excess of SS and approximately the expected number of FS. These five broods are homogeneous with respect to genotype frequencies (table 2 ) and give overall ratios of $0 \cdot 048: 0.549: 0 \cdot 403$. A further nine broods have an excess of FF a deficiency of SS and the expected number of FS; again they are homogeneous with respect to genotype proportions (table 2). If the actual homozygous genotypes are ignored and homozygotes are categorised as being either under-represented or over-represented then the two sets of data are homogeneous $\left(\chi^{2}=\right.$ $1 \cdot 574,2$ df $P>0 \cdot 05)$.

The third cluster of three broods has a lower than expected frequency of heterozygotes and a higher than expected frequency of the FF homozygote. Again the genotype proportions are homogeneous (table 2).

\section{DISCUSSION}

How can these results be explained? When broods are scored around one in every twenty will lead to a rejection of $H_{0}$ as a result of type 1 statistical errors when a critical probability of 5 per cent is used. Of the 211 broods reported here we would therefore expect around ten significant departures from expectation. We observe 37 departures from expectation many of which are highly significant and it follows that some other explanation must be advanced for the majority of these observations.

Previous work (Edwards and Heath, 1983), based on a small number of broods in which all the distortions went in one direction, had suggested that selection might be responsible for the distorted ratios at this locus, either through gametic or early zygotic selection. The data presented here renders a selective explanation much less likely since distortions occurred in both directions in all three maternal genotypes. This would require for example that there were two sorts of FS females, one that selects against $\mathrm{F}$ gametes or FF zygotes, the other that selects against $\mathrm{S}$. It would also require very strong selection to produce the observed distortions.

A simpler explanation is based on multiple mating, a phenomenon that has been described in

Table 2 Offspring genotype ratios in distorted broods segregating for three genotypes. Figures in parentheses are relative genotype frequencies. Legend as for Table 1 except: $\mathrm{df}=$ degrees of freedom

\begin{tabular}{|c|c|c|c|c|c|c|c|c|}
\hline \multirow[b]{2}{*}{ Female } & \multirow[b]{2}{*}{$N$} & \multirow[b]{2}{*}{$n$} & \multicolumn{3}{|c|}{$\begin{array}{l}\text { Offspring genotypes } \\
\text { and ratios }\end{array}$} & \multirow[b]{2}{*}{$\chi^{2}$} & \multirow[b]{2}{*}{$\mathrm{df}$} & \multirow[b]{2}{*}{$P$} \\
\hline & & & $\mathrm{FF}$ & FS & SS & & & \\
\hline 7) & & $\int 9$ & $\begin{array}{l}129 \\
(0 \cdot 402)\end{array}$ & $\begin{array}{l}173 \\
(0.539\end{array}$ & $\begin{array}{l}19 \\
(0.059)\end{array}$ & $20 \cdot 365$ & 16 & ns \\
\hline FS & 54 & 5 & $\begin{array}{l}14 \\
(0.061)\end{array}$ & $\begin{array}{l}116 \\
(0 \cdot 567)\end{array}$ & $\begin{array}{l}99 \\
(0.432)\end{array}$ & $11 \cdot 374$ & 8 & $\mathrm{~ns}$ \\
\hline 9) & & 3 & $\begin{array}{l}50 \\
(0 \cdot 376)\end{array}$ & $\begin{array}{l}48 \\
(0 \cdot 361)\end{array}$ & $\begin{array}{l}35 \\
(0.263)\end{array}$ & $3 \cdot 692$ & 4 & $\mathrm{~ns}$ \\
\hline
\end{tabular}


terrestrial isopods (see Introduction). For example an FF female mating with an FF male and then an FS male (or vice versa) will produce offspring in the ratio 75 per cent $F F: 25$ per cent FS, provided that gametes from both males have equal probabilities of successful fertilisation (i.e., no displacement of sperm). Heterozygous females mating with any combination of two different males will produce broods with all three genotypes of offspring. Matings involving an FF and an SS male would be formally equivalent to mating with an FS male (if there is no displacement), yielding the familiar $1: 2: 1$ ratio. Matings of a heterozygous female with FS and FF males or FS and SS males would produce broods with 50 per cent heterozygotes, $37 \cdot 5$ per cent of one homozygote and 12.5 per cent of the other. On this hypothesis we should expect to find symmetrical distortions in offspring ratios of both homozygous females and also in broods of heterozygous mothers. This is exactly what is observed in categories $1,2,5,6,7$ and 8. This explanation is further supported by the observation that the proportion of females producing distorted broods is not different for the three maternal genotypes $\left(\chi^{2}=3 \cdot 814,2 \mathrm{df} P>0 \cdot 05\right)$. Because heterozygous females segregating for only two offspring genotypes cannot reveal the presence of multiple mating (see below) this calculation is based on the data for heterozygous females from table 2 . The three observations in category 9 are omitted as they cannot be due to multiple mating (including them gives $\chi^{2}=3.56 P>0.05$ ). While distorted offspring ratios of homozygous mothers fit with the expectation based on an equal fertilisation success of both males, the data from heterozygous females in categories 7 and 8 do not $\left(\chi^{2}=\right.$ $19 \cdot 30,2$ df $P<0 \cdot 001)$. The commoner homozygote is too common, as is the heterozygote, whilst the rarer homozygote is too rare. This suggests that either there is sperm precedence in heterozygotes, although even this cannot give rise to frequencies of heterozygous progeny in excess of 0.5 or that there is some additional selective factor in operation. The problem with the latter explanation is that it requires two types of FS females, some that select against one allele (in either the gametic or the early zygotic phase) and some that select against the other allele. One possible speculative explanation is that selection arises as a result of competitive interactions between gametes or zygotes in a negative frequency dependent fashion. For example if a homozygous zygote survived less well in the maternal environment when it was initially rare, then the original distortion produced by multiple mating would be exacerbated.
A hypothesis of multiple mating cannot explain the results in categories 3,4 and 9. Categories 3 and 4, each with one example, are of heterozygous females producing only two types of offspring in non-Mendelian ratios. Heterozygous females should produce either non-distorted broods (as a result of a single mating, or a multiple mating with two identical males) or a distorted brood with three types of offspring (as a result of multiple mating with two different males, category 7 and 8 ). Categories 3 and 4 with a distorted ratio of only two types of offspring show neither pattern. They could conceivably be misclassified examples of type 7 and 8 in which, just by chance one of the homozygotes is missing. However they deviate significantly from the ratios displayed in categories 7 and 8 ( 3 vs. $7, \chi^{2}=7.538,2$ df $P<0.05 ; 4$ vs. 8 , $\left.\chi^{2}=12 \cdot 819,2 \mathrm{df}, P<0 \cdot 001\right)$. Individually the three results in category 9 deviate from the expected $1: 2: 1$ ratio at the 5 per cent significance level. Taken together they also deviate significantly from the pattern shown by categories 7 and 8 when these are pooled on the basis of "under-represented" and "over-represented" homozygotes $\left(\chi^{2}=50 \cdot 67\right.$, 2 df $P<0.001)$. It is not possible to decide whether the ratios in these five broods were due to type I errors or whether they were the result of some other phenomenon. (Of course some, but not all, of the ratios in categories $1,2,5,6,7$ and 8 will be due to type I errors.)

Although multiple mating does not account for all of the obs ed departures and although other mechanisms :e.g., selection, type I errors) can be invoked, multiple mating provides the most parsimonious explanation of the results. It is also compatible with two other observations from this population. Khazaeli (1980) gives phenotypic ratios in broods (of fertilised females taken from the natural population) segregating at a body colour locus. There was a common recessive morph "grey" and a rare morph "pattern" (frequency = $0 \cdot 15)$, controlled by a dominant allele. Out of 61 grey females producing broods segregating for grey and pattern, 15 showed distorted ratios, all with an excess of grey offspring. Overall the ratio in these 15 broods was 375 grey:92 pattern a frequency of grey of $0 \cdot 803$. Both the proportion of distorted broods $(15 / 61=24$ per cent $)$ and the frequency of the common type in the broods $(0.803)$ are very similar to those reported here. Distorted ratios of the type observed by Khazaeli (1980) would be accounted for by a mating between a homozygous grey recessive female and two males, one a heterozygous pattern, the other a homozygous grey recessive. The other relevant observation is that Riddoch (1987) gives one 
instance of multiple mating in the laboratory in this species.

Extrapolation to the isopod A. aquaticus could also explain some genetic data given by Verspoor (1982). He used male/female pairs taken in precopula from a natural population to examine the genetic basis of the PGI and phosphoglucomutase (PGM) polymorphisms. Out of the broods of 20 pairs analysed for PGM, three (involving a $3 / 2$ male and a $2 / 3$ female) showed significant deviations from the expected $1: 1$ ratio. Two had an excess of $3 / 2$ and one an excess of $2 / 2$. He ascribed this to sampling error but it could equally well have arisen as a result of a previous mating. Furthermore another $2 / 2$ female found in precopula with a $3 / 3$ male produced both $3 / 2$ and $2 / 2$ offspring, indicative of an earlier mating with a $2 / 2$ or a $2 / 3$ male.

From the data presented here it is possible to obtain a minimum estimate of the proportion of females mating with two males. Leaving aside categories 3, 4 and 9 out of 147 segregating broods, 35 were distorted i.e., 23.8 per cent (a figure very close to that for the colour polymorphism quoted earlier). To this would have to be added those multiple matings which will yield undistorted ratios (where males are $\mathrm{FF}+\mathrm{SS}, \mathrm{FS}+\mathrm{FS}$ ). This suggests that a considerable proportion of females had been fertilised by two males which comes as something of a surprise, given the life history details already described and the general observation that males are less common than females in the population (Riddoch, 1988). It compares quite closely with the figure of 30 per cent multiple matings reported by Sassman (1978) for the terrestrial isopod Porcellio dilatatus, although it is lower than the figure of 80 per cent given by the same author for $P$. scaber. It seems that $S$. rugicauda may be behaving in a rather similar way to the intertidal amphipod Platorchestia platensis (McDonald, 1989) where multiple mating has been described, although in another intertidal amphipod Gammarus oceanicus broods are apparently sired by only one male (Seigismund, 1985).

What is the significance of this finding for the genetics of the population, particularly with regard to the PGI polymorphism? It does not invalidate the results of the selection component analysis (Heath et al., 1988) which used mother/single offspring combinations, an analysis developed for organisms where multiple mating may occur (Christiansen and Frydenberg, 1973). Multiple mating per se would not be expected to alter the dynamics of a polymorphism unless either the efficiency of multiple mating depends on genotype (e.g., Prout and Bundgaard, 1977) or multiple mating leads to other types of selective interaction between gametes or developing zygotes. The relative proportions of the different types of multiple mating displayed in tables 1 and 2 do not suggest any dependence of multiple mating efficiency on either male or female genotype, although sample sizes are small. However the results from heterozygous mothers with broods segregating for three offspring genotypes do suggest that some other factor is in operation.

\section{REFERENCES}

CHRISTIANSEN, F. B. AND FRYDENBERG, O. 1973. Selection component analysis of natural populations using population samples including mother-offspring combinations. Theor. Pop. Biol., 4, 425-445.

EDWARDS, J. P. 1981. Analysis of an Enzyme Polymorphism in the Isopod Sphaeroma Rugicauda (Leach). Ph.D. Thesis, University of Essex.

EDWARDS, J. P. AND HEATH, D. J. 1983. Dynamics of an enzyme polymorphism in the isopod, Sphaeroma rugicauda (Leach). II Sexual, gametic and fecundity selection. Heredity, 51, 477-486.

ENDLER, J. A. 1986. Natural Selection in the Wild. Princeton Univeristy Press, Princeton, New Jersey.

HEATH, D. J. AND KHAZAELI, A. A. 1985. Population dynamics of the estuarine isopod Sphaeroma rugicauda. Estuarine, Coastal and Shelf Science, 20, 105-116.

HEATH, D. J., RIDDOCH, B. J., RATFORD, J. R. AND CHILDS, D. 1988. Selection component analysis of the PGI polymorphism in Sphaeroma rugicauda. Heredity, 60, 229-235.

JOHNSON, C. 1982. Multiple insemination and sperm storage in the isopod, Venezillo evergladensis. Schultz, 1963. Crustaceana, 42, 225-232.

KHAZAELI, A. A. 1980. Ecological Genetics of the Polymorphic Isopod. Sphaeroma Rugicauda (Leach), Ph.D. Thesis, University of Essex.

McDONALD, J. H. 1989. Selection component analysis of the Mpi locus in the amphipod Platorchestia platensis. Heredity, 62, 243-249.

PROUT, T. AND BUNDGAARD, J. 1977. The population genetics of sperm displacement. Genetics, 85, 95-124.

RIDDOCH, B. J. 1987. Selection Component Analysis of the PGI Polymorphism in Sphaeroma Rugicauda. Ph.D. Thesis, University of Essex.

RIDLEY, M. 1983. The Explanation of Organic Diversity. Oxford University Press, Oxford.

SASSMAN, C. 1978. Mating systems in procellionid isopods: multiple paternity and sperm mixing in Porcellio scaber, Heredity, 41, 385-397.

SIEGISMUND, H. R. 1985. Genetic studies of Gammarus. IV. Selection component analysis of the Gpi and Mpi loci in Gammarus oceanicus. Hereditas, 102, 241-250.

SMITH, R. L. 1984. Sperm Competition and the Evolution of Animal Mating Systems. Academic Press, London.

VERSPOOR, E. 1982. Description and genetics of the glucose phosphate isomercase and phosphogluco-mutase polymorphisms in Asellus aquaticus. Biochem. Genet., 20, 891905.

WAAGE, J. K. 1986. Evidence for widespread sperm displacement ability among Zygoptera (Odonata) and the means for predicting its presence. Biol. Journ. Linn. Soc. 28, $285-$ 300 . 